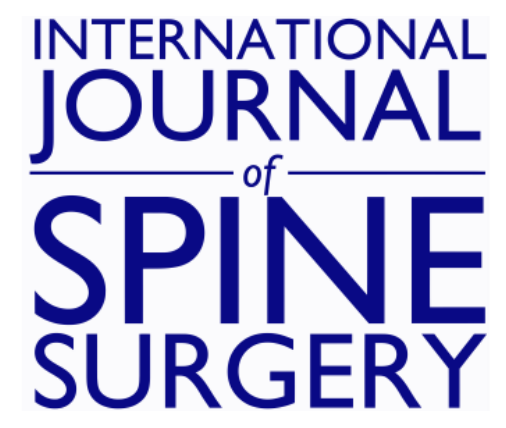

\title{
Validity and reliability of a novel patient reported outcome tool to evaluate post-operative dysphagia, odynophagia, and voice (DOV) disability after anterior cervical procedures
}

Joseph A Sclafani, Deborah I. Ross, Brian H. Weeks, Michelle Yang and Choll W. Kim

Int J Spine Surg 2017, 11 (5)

doi: https://doi.org/10.14444/4035

http://ijssurgery.com/content/11/5/35

This information is current as of April 26, 2023.

Email Alerts Receive free email-alerts when new articles cite this article. Sign up at:

http://ijssurgery.com/alerts

The International Journal of Spind Surgerbhttp://ijssurgery.com/ by guest on April 26, 2 2397 Waterbury Circle, Suite 1, 


\section{Validity and reliability of a novel patient reported outcome tool to evaluate post-operative dysphagia, odynophagia, and voice (DOV) disability after anterior cervical procedures}

Joseph A Sclafani, MD, ${ }^{1}$ Deborah I. Ross, CCC-SLP, 2 Brian H. Weeks, MD, ${ }^{3}$ Michelle Yang, BS, ${ }^{1}$ Choll W. Kim, MD, PhD 1

${ }^{1}$ Spine Institute of San Diego, Minimally Invasive Spine Center of Excellence, ${ }^{2}$ San Diego Speech Therapy, San Diego, CA, ${ }^{3}$ Senta Clinic, San Diego, CA

\section{Abstract}

Background

Existing evaluative instruments for dysphagia, odynophagia, and voice disturbance are cumbersome, focus predominately on dysphagia, and often require administration by a certified Speech Pathologist. This study was conducted to utilize widely accepted instruments such as the American Speech and Hearing Association's National Outcomes Measurement System (NOMS) and VAS pain scales to validate a novel, patient-reported instrument that quantifies the severity of post-operative dysphagia, odynophagia, and voice disabilities (DOV).

\section{Methods}

The DOV was developed and subjected to multiple rounds of face and content validation by representative patient cohorts and a panel of clinical experts. An established, prospective clinical registry was utilized to collect pre and post-operative VAS-swallow related pain and DOV measurements for subjects with recent anterior cervical procedures ( $\mathrm{n}=25$ content validation, $\mathrm{n}=20$ criterion validation), or recent lumbar decompressions $(\mathrm{n}=33)$. NOMS evaluations were performed by a certified Speech Language Pathologist on the first post-operative day after minimally invasive anterior approaches to cervical reconstruction were performed in the criterion validation cohort.

Results

Content validity: Subjects with a recent anterior cervical procedure reported a significant increase in postoperative dysphagia (pre-op: $0.13 \pm 0.35$, post-op: $1.08 \pm 1.41, \mathrm{p}=0.01$ ), odynophagia (pre-op: $0.24 \pm 0.69$, post-op: $0.84 \pm 0.90, \mathrm{p}=0.001$ ), and voice (pre-op: $0.10 \pm 0.41$, post-op: $0.88 \pm 0.92, \mathrm{p}=0.0004$ ) disturbance. In contrast, subjects with a recent lumbar procedure did not demonstrate a significant increase in post-operative dysphagia, odynophagia, or voice disturbance ( $\mathrm{p}>0.05)$.

Criterion validity: Chi-squared contingency testing for independence between converted NOMS and DOV instrument scores accepted linkage between the two instruments for dysphagia X2(DF: 12, n=20, Expected: 21.03, Observed: 24.4, p: 0.02) and voice X2(DF: 6, n=20, Expected: 12.60, Observed: 21.28, p: 0.002) dimensions. Similarly, converted swallow related VAS and DOV odynophagia instruments demonstrated linkage X2(DF: 9, n=20, Expected: 16.92 , Observed: 24.21, p: 0.004).

Internal Reliability: Chronbach's alpha coefficient of reliability was 0.74 between all DOV survey dimensions.

\section{Conclusions}

The DOV survey is a valid patient-reported instrument to rapidly and reliably detect post-operative swallow and voice dysfunction.

CERVICAL SPINE

KEYWORDS: MINIMALLY INVASIVE CERVICAL SURGERY, DYSPHAGIA, ODYNOPHAGIA, VOICE DISTURBANCE, SWALLOW DYSFUNCTION, PATIENT REPORTED OUTCOME, INSTRUMENT VALIDATION

VOLUME 11 ISSUE 5 DOI: 10.14444/4035 PAGES 285 - 292

\section{Introduction}

Prevertebral soft tissue swelling (PSTS) is a common post-operative radiographic finding associated with Downloaded from http://ijssurgery.com/ by guest on April 26, 2023 anterior cervical operative approaches (Figure 1) $\cdot{ }^{1-4}$

Post-operative prevertebral swelling has been reported to result in severe airway compromise in up to $5-6 \%$ of all anterior cervical procedures and in rare 
cases may require emergent intubation or tracheostomy. ${ }^{2,4-10}$ Various modifications have been proposed to decrease post-operative morbidities after anterior approaches to the cervical spine, including implantation of zero-profile cervical interbody spacer systems and the intraoperative deposition of retropharyngeal steroids. ${ }^{11-13}$ Nevertheless, there remains a dearth of patient reported outcomes to support the use of these technologies in the current clinical setting.

Existing evaluative instruments such as the American Speech and Hearing Association's National Outcomes Measurement System (NOMS) are burdensome and require administration by a highly trained practitioner..$^{14}$ Although this instrument is a validated and reliable method to screen for dysphagia or voice disturbance, it is not typically feasible to obtain a complete post-operative NOMS assessment on every patient after an anterior cervical approach. As a result, cases of mild to moderate post-operative disability that would benefit from an advanced dysphagia or voice dysfunction workup may be overlooked.

This study was conducted to construct and validate a novel, patient-reported survey to quantify the severity of post-operative dysphagia, odynophagia and voice disturbance (DOV). The DOV was designed to function as a sensitive screening instrument that could rapidly and reliably detect post-operative swallow and voice dysfunction without overburdening health-care resources.

An instrument can be deemed valid if it satisfactorily demonstrates sufficient internal reliability and ac-

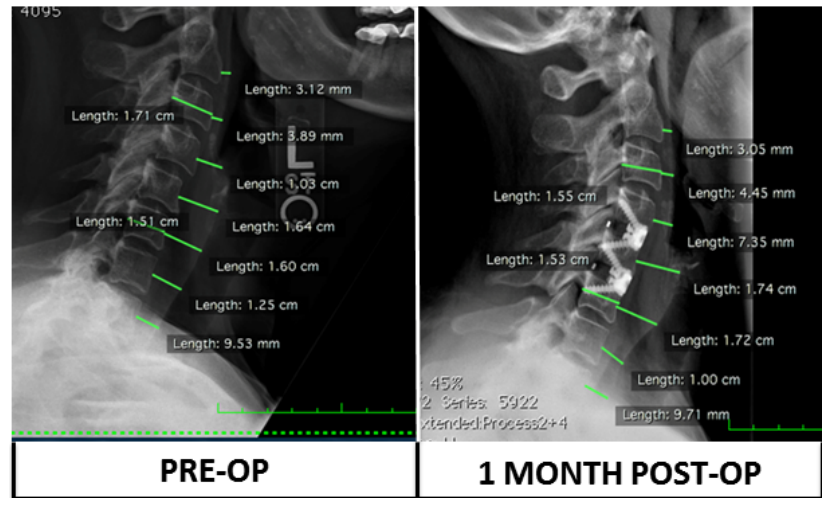

Fig. 1. An example of prevertebral soft tissue swelling after an anterior approach to cervical fusion. Such swelling can lead to dysphagia, odynophagia, or voice changes. ceptable face, content, and criterion validity. ${ }^{15,16}$ Face validity, best determined by a diverse panel of experts, qualitatively describes the instrument's superficial ability to appropriately measure the desired outcome. Content validity is a quantitative assessment of the instrument's capacity to measure the desired outcome with sufficient sensitivity. Criterion Validity describes the performance of the instrument against a previously validated standard for the desired outcome. ${ }^{16}$

Validation of the DOV was accomplished in four phases: (1) Initial face validity was established by a panel of experts as well as a population of patients with self-reported swallow dysfunction, (2) content validity was assessed through distribution of the DOV to subgroups at high and low risk of swallow dysfunction, (3) criterion validity was established through utilization of widely accepted and previously validated practitioner-administered outcome instruments (NOMS-Swallow, NOMS-Voice, VAS of swallow related pain) to validate the DOV survey, (4) internal reliability of the DOV survey was evaluated utilizing Chronbach's alpha statistical analysis.

\section{Methods}

\section{DOV Questionnaire Development: Face and Content Validity} DOV questionnaires (Figure 2) were comprised of 3 distinct categories of disability: dysphagia (4 points), odynophagia (3 points), and voice (3 points). A multi-specialty panel of experts (Speech Language Pathology (DR), Otolaryngology (BW), Orthopaedic Spine Surgery (CWK), and Physical Medicine and Rehabilitation (JAS)) evaluated the DOV questionnaire for overall appearance, relevance and representation of its elements.

The DOV questionnaire was then administered to a cohort of patients with a recent anterior cervical procedure for further face validation by a representative sample of individuals with swallow dysfunction. Patient-modified surveys were redistributed to the expert panel to reassess both accuracy and the connection among asked questions and measured variables prior to proceeding with criterion validation. 
After face validity was achieved, the DOV was administered preoperatively, and at one week post-op to two distinct patient subgroups for content validation. The first group (Group AC), underwent an anterior cervical procedure and represented a patient subgroup at high risk for post-operative DOV disability. The second group (Group LD) underwent a lumbar decompression procedure and was representative of a subgroup with recent intubation that was otherwise at low risk for DOV disability.

\section{Survey Administration and Conversion for Criterion Validity}

DOV questionnaires were completed on postoperative day one by patients that had undergone minimally invasive anterior cervical discectomy and fusion. A single, experienced Speech Language Pathologist also performed a complete NOMS evalu- ation for each subject during the same inpatient therapy session. All collected data was stored within an IRB approved, established prospective registry database. $^{17}$

Analysis was performed on dysphagia and voice components of the DOV questionnaire and compared to the NOMS swallow and voice disability ratings assigned by the treating Speech Language Pathologist. NOMS dysphagia and voice scores were converted to an equivalent DOV score based on comparable functional disability (eg. A NOMS category that recommends an NPO diet was converted to a DOV disability score that describes incapability of swallowing all textures and consistencies). Odynophagia was evaluated through a comparison of swallow-related VAS (VAS-SR) pain and the odynophagia dimension of the DOV survey. VAS-SR pain scores were con-

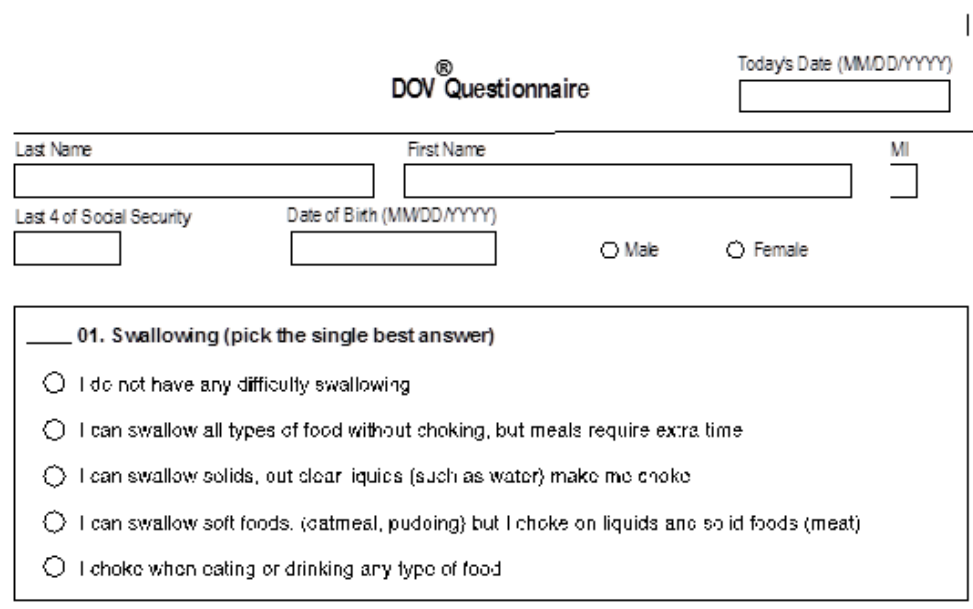

\begin{tabular}{|c|}
\hline _ 02 . Voice (pick the single best answer) \\
\hline$O$ My woice is strong and clear all day long \\
\hline$O$ My voire is hoarse but pesple san hear me even in a noisy envircnment \\
\hline My voice is hoarse and ceople car hear me only in a quie1 environment \\
\hline Miy veice is usually too sicak to talk with othere \\
\hline
\end{tabular}
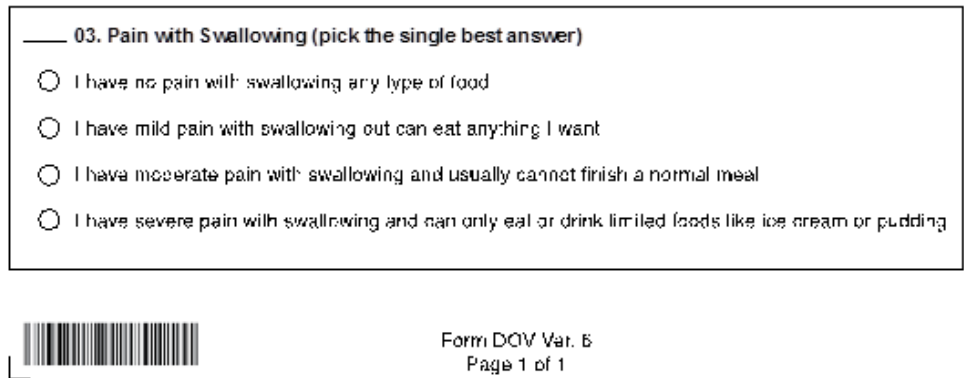

Fig. 2. The patient administered Dysphagia, Odynophagia, and Voice (DOV) survey. 
verted to an equivalent DOV-Odynophagia severity score prior to criterion validity analysis (Table 1, Figure 3).

\section{Statistical analyses}

Statistical analysis for content validity utilized unpaired t-tests to compare one-week post-operative dysphagia, odynophagia and voice disability scores between group AC and group LD. Significance was defined as $\mathrm{p}<0.05$.

Criterion validity was achieved utilizing convergent analyses between converted NOMS swallow and voice disability scores and DOV dysphagia and voice scores, respectively. Additional convergent analysis was conducted between DOV odynophagia dimension and VAS-SR pain scores. A null hypothesis of independence between instruments was stated for each convergent analysis $(\mathrm{p}<0.05$ represents equivalence between the two instruments).

Reliability was assessed with Chronbach's alpha test of internal reliability. A minimum Chronbach's alpha coefficient of 0.7 was considered satisfactory for group-level comparisons, which is consistent with historically accepted values. ${ }^{18}$ All statistical analyses were completed using the XLSTAT package for Excel and the Wessa Chronbach's alpha calculator. ${ }^{19}$ Values are reported as mean \pm standard deviation, unless otherwise stated.

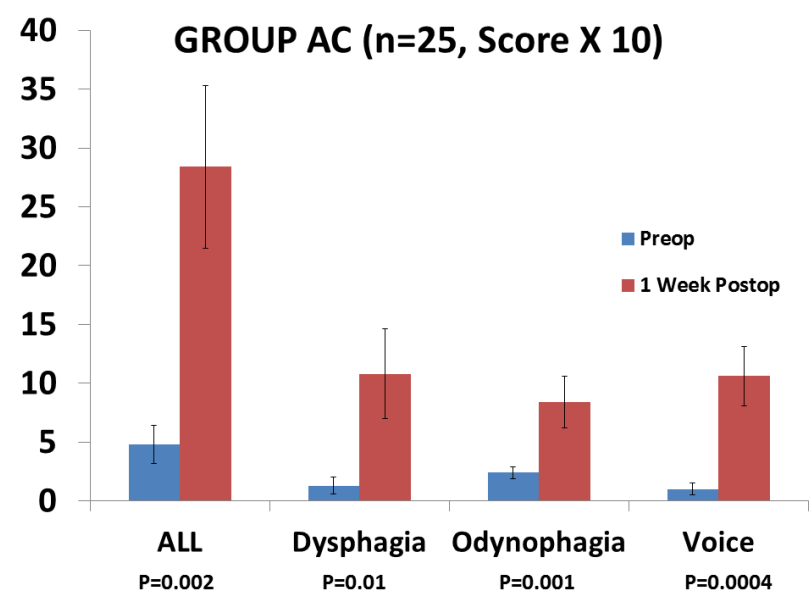

Fig. 3. Cervical patients $(A C)$ reported a significant increase in post-operative dysphagia, odynophagia, and voice disability.

\section{Results}

\section{Content Validity}

A total of 25 cervical (Group AC: 22 multi-level anterior cervical discectomy and fusion procedures, 3 thyroidectomy procedures) and 33 non-cervical (Group LD: 33 lumbar decompression procedures) subjects completed the pre and post-operative DOV. Group AC reported a significant increase in postoperative dysphagia (pre-op: $0.13 \pm 0.35$, post-op: $1.08 \pm 1.41, \mathrm{p}=0.01$ ), odynophagia (pre-op: $0.24 \pm 0.69$, post-op: $0.84 \pm 0.90, \mathrm{p}=0.001$ ), and voice (pre-op: $0.10 \pm 0.41$, post-op: $0.88 \pm 0.92, \mathrm{p}=0.0004$ ) distur-

\begin{tabular}{|c|c|c|}
\hline \multicolumn{3}{|c|}{ Odnophagia Conversion } \\
\hline VAS & & DOV \\
\hline 7 to 10 & Severe pain & 3 \\
\hline 4 to 7 & Moderate pain & 2 \\
\hline 1 to 3 & Mild pain & 1 \\
\hline 0 & No pain & 0 \\
\hline \multicolumn{3}{|c|}{ Dysphagia Conversion } \\
\hline Noms & & DOV \\
\hline 1 & $\mathrm{NPO}+\mathrm{PEG}$ & 4 \\
\hline 2 & $\mathrm{NPO}+\mathrm{PEG}$, trials with therapy only & 4 \\
\hline 3 & Peg + Chopped \& Honey thick & 3 \\
\hline 4 & Thick liquids + Chopped or soft $\&$ nectar & 2 \\
\hline 5 & Either soft or nectar thick & 1 \\
\hline 6 & Extra time to eat but regular and thins & 0 \\
\hline 7 & Normal, regular and thins & 0 \\
\hline \multicolumn{3}{|c|}{ Voice Conversion } \\
\hline Noms & & DOV \\
\hline 1 & No Voice & 3 \\
\hline 2 & Cannot functionally communicate & 3 \\
\hline 3 & Functional but severely limited & 2 \\
\hline 4 & Moderate limitation & 2 \\
\hline 5 & Min-Mod limitation & 1 \\
\hline 6 & Minimal limitation & 1 \\
\hline 7 & Normal & 0 \\
\hline
\end{tabular}


bance (Figure 3). Group LD did not demonstrate a significant increase in post-operative dysphagia (preop: $0.24 \pm 0.66$, post-op: $0.33 \pm 0.69, \mathrm{p}=0.42$ ), odynophagia (pre-op: $0.09 \pm 0.30$, post-op: $0.9 \pm 0.38$, $\mathrm{p}=0.99$ ), or voice (pre-op: $0.51 \pm 1.0$, post-op: $0.54 \pm 1.2, \mathrm{p}=0.26$ ) disability (Figure 4). Group AC reported more post-operative disability than Group LD in all subscales of the DOV questionnaire $(\mathrm{p}<0.05)$

\section{Criterion Validity}

A total of 20 literate, primary English speaking adult subjects (13 female: 7 male, Age: $62.7 \pm 13.5$ years) completed DOV, NOMS, and VAS-SR instruments on post-operative day one after a minimally invasive anterior cervical discectomy and fusion with a zero profile interbody spacer (single-level: $n=4$, two-level: $\mathrm{n}=12$, two-level with single level corpectomy: $\mathrm{n}=1$, three-level: $n=2$, four-level: $n=1$ ). Overall, summated DOV scores for the cohort were $3.1 \pm 2.4$ (dysphagia subscale $0.95 \pm 1.2$, odynophagia subscale $1 \pm 0.80$, voice subscale $1.2 \pm 0.9$, Figure 5). Overall, summated converted scores for the NOMS and VAS instruments were 3.2 \pm 2.1 (NOMS swallow dysfunction subscale 1.1 \pm 1.2 , VAS-SR subscale 1.1 \pm 0.89 , NOMS voice dysfunction subscale $1.0 \pm 0.56$, Figure 6 ).

Chi-squared contingency testing for independence between converted NOMS swallow and DOV dysphagia dimensions accepted the alternative hypothesis of linkage between the two instruments $\mathrm{X}^{2}(\mathrm{DF}$ : 12, n=20, Expected: 21.03, Observed: 24.4, p: 0.02). Contingency testing for independence between con-

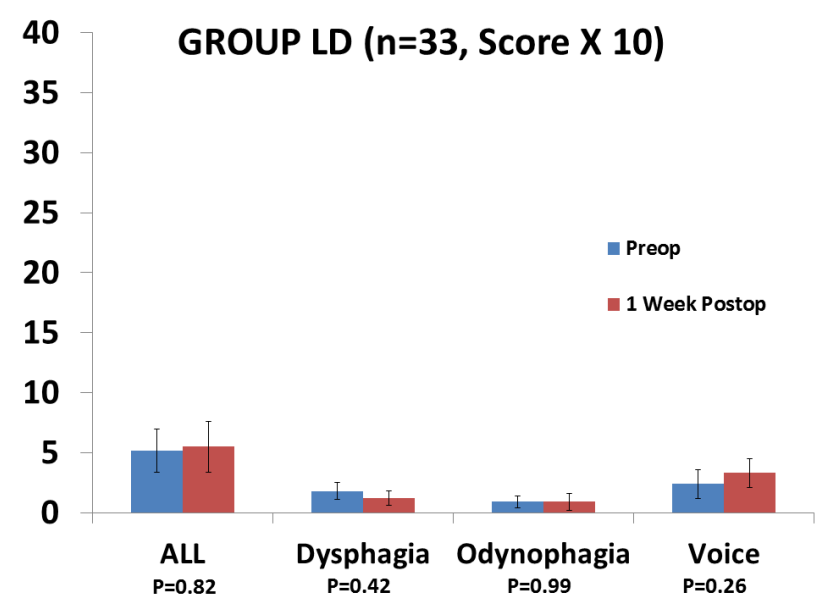

Fig. 4. The non-cervical group (LD) did not demonstrate a significant increase in post-operative dysphagia $(p=0.21)$, odynophagia $(p=0.5)$, or voice $(p=0.13)$ disability. verted NOMS voice and DOV voice dimensions also rejected inter-survey independence and accepted linkage between the instruments $\mathrm{X}^{2}(\mathrm{DF}: 6, \mathrm{n}=20$, Expected: 12.60 , Observed: 21.28 , p: 0.002). Similarly, Chi-squared testing for independence between converted VAS-SR and DOV odynophagia dimensions accepted inter-survey linkage $X^{2}(\mathrm{DF}: 9, \mathrm{n}=20$, Expected: 16.92 , Observed: 24.21, p: 0.004).

\section{Internal Reliability}

Internal reliability between all dimensions of the DOV instrument was calculated to be acceptable (Chronbach's alpha reliability coefficient: 0.74 ). The

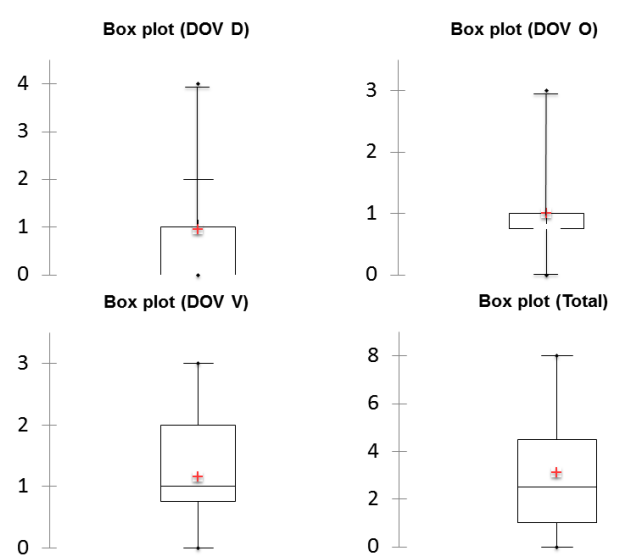

Fig. 5. Box and whisker plot depicting the score distribution of each DOV subscale. Mean value represented by (+), the box represents quartiles 1 through 3 intersected by the median value. Whiskers represent the maximum and minimum data points.

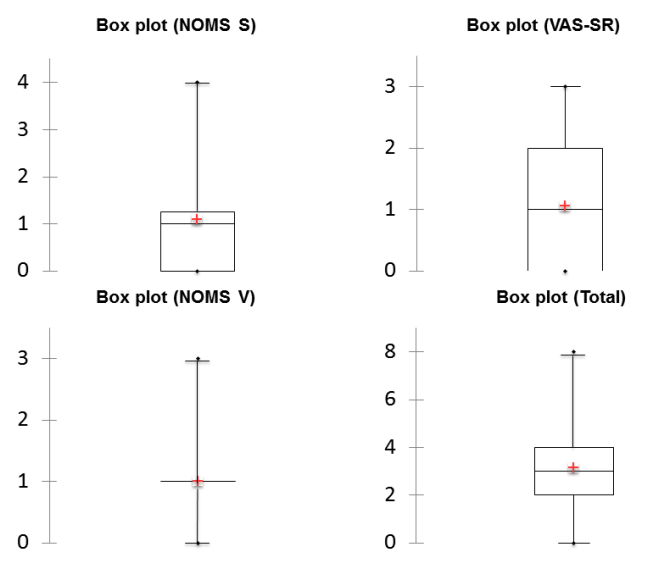

Fig. 6. Box and whisker plot depicting the score distribution of each NOMS subscale. Mean value represented by (+), the box represents quartiles 1 through 3 intersected by the median value. Whiskers represent the maximum and minimum data points. NOMS V mean, median, quartile 1 , and quartile 3 values were all 1 , which is representative of a minimal to min-moderate limitation. 
reliability coefficient between dysphagia and voice subscales was 0.81 , the coefficient between dysphagia and odynophagia was 0.58 , and the coefficient between odynophagia and voice was 0.46 (Table 2).

\section{Discussion}

This study utilized the widely accepted, NOMS and VAS-SR surveys to successfully validate the patientreported DOV instrument. The DOV demonstrated acceptable face validity, content validity, criterion validity, and internal reliability when used to assess swallow and voice disabilities in a patient population with recent anterior prevertebral soft tissue disruption.

Anterior cervical procedures and their consequent PSTS are major contributors to post-operative dysphagia. However, to the best of our knowledge, it has not been directly correlated to post-operative odynophagia or voice disturbances. ${ }^{1,420}$ Our content validation cohort demonstrated significantly more disability in all tested domains in the anterior cervical surgery group compared to the lumbar surgery group, including swallow related pain and subjective voice disturbance. Irritation of the recurrent laryngeal nerve and the external branch of the superior laryngeal nerve are the most commonly described causes of vocal dysfunction after anterior cervical operative approaches. Yet, it has been reported that 50\% of individuals with a unilateral recurrent laryngeal nerve palsy are clinically asymptomatic. ${ }^{21}$ Another proposed mechanism of post-operative vocal dysfunction is iatrogenic damage to the cervical strap muscles, leading to subtle changes in motility and tension properties of the internal and external laryngeal muscles during phonation. ${ }^{22}$ Early detection of patients with subjective voice disturbance by the DOV instrument would not only expedite treatment plans focused on vocal rehabilitation, but also facili-

Table 2. Chronbach's Alpha Internal Reliability Values.
\begin{tabular}{|l|r|}
\hline Items & Cronbach Alpha \\
\hline All items & 0.7415 \\
\hline Dysphagia excluded & 0.4631 \\
\hline Odynophagia excluded & 0.8109 \\
\hline Voice excluded & 0.5823 \\
\hline
\end{tabular}

tate investigation into the epidemiology of voice morbidities.

The DOV can also function as a discriminative and evaluative instrument to assess new technologies and surgical techniques designed to reduce postoperative swallow and voice dysfunction. Recent advancements in zero profile spacer systems and minimally invasive muscle sparing approaches to cervical arthrodesis have shown positive initial radiographic PSTS trends, but still lack convincing patient reported improvement in voice and swallow outcomes over preceding technologies. ${ }^{11,23-25}$ Other techniques aimed at managing anatomic etiologies of dysphagia, such as botulinum toxin injections for cricopharyngeal dysfunction or various approaches to surgical resection of a Zenker's diverticulum, would also benefit from an easily administered patient reported instrument of swallow and voice dysfunction. ${ }^{26-28}$

Comprehensive evaluation of swallow dysfunction may be achieved with either a modified barium swallow (MBS) or Fiber-optic endoscopic examination of the swallow (FEES). ${ }^{29}$ Although both diagnostic procedures have been shown to identify appropriate dietary consistencies and detect signs of dysphagia (laryngeal penetration, aspiration, pharyngeal residue), FEES is also able to visualize pathophysiologic causes of dysphonia and odynophagia. ${ }^{29-31}$ However, selection of the appropriate examination is often clinically difficult given the largely congruent set of indications between the MBS and FEES assessments. Implementation of the DOV as a screening tool to rapidly detect individuals at the highest risk for clinical aspiration, both with and without dysphonia or odynophagia, would facilitate selection of the appropriate diagnostic modality.

A limitation of this study is the small and relatively homogenous sample of patients used for criterion validation. Although the DOV was designed to detect postoperative swallow and voice disability after multiple types of anterior cervical approaches, all subjects were from a single site and underwent an anterior cervical reconstruction with a zero profile interbody spacer system. Appraisal of the DOV in different post-operative settings would increase confidence in the generalizability of the results. 


\section{References}

1. Stachniak JB, Diebner JD, Brunk ES, Speed SM. Analysis of prevertebral soft-tissue swelling and dysphagia in multilevel anterior cervical discectomy and fusion with recombinant human bone morphogenetic protein-2 in patients at risk for pseudarthrosis: clinical article. Journal of Neurosurgery: Spine.

2011;14(2):244-9.

2. Suk K-S, Kim K-T, Lee S-H, Park S-W. Prevertebral soft tissue swelling after anterior cervical discectomy and fusion with plate fixation. International orthopaedics. 2006;30(4):290-4.

3. Frempong-Boadu A, Houten JK, Osborn B, Opulencia J, Kells L, Guida DD, et al. Swallowing and speech dysfunction in patients undergoing anterior cervical discectomy and fusion: a prospective, objective preoperative and postoperative assessment. Journal of spinal disorders \& techniques.

2002;15(5):362-8.

4. Martin RE, Neary MA, Diamant NE. Dysphagia following anterior cervical spine surgery. Dysphagia. 1997;12(1):2-8.

5. Fountas KN, Kapsalaki EZ, Nikolakakos LG, Smisson HF, Johnston KW, Grigorian AA, et al. Anterior cervical discectomy and fusion associated complications. Spine. 2007;32(21):2310-7.

6. Riley III LH, Skolasky RL, Albert TJ, Vaccaro AR, Heller JG. Dysphagia after anterior cervical decompression and fusion: prevalence and risk factors from a longitudinal cohort study (presented at the 2004 CSRS Meeting). Spine. 2005;30(22):2564-9.

7. Smith-Hammond CA, New KC, Pietrobon R, Curtis DJ, Scharver CH, Turner DA. Prospective analysis of incidence and risk factors of dysphagia in spine surgery patients: comparison of anterior cervical, posterior cervical, and lumbar procedures.

Spine. 2004;29(13):1441-6.

8. Sagi HC, Beutler W, Carroll E, Connolly PJ. Airway complications associated with surgery on the anterior cervical spine. SPINE-PHILADELPHIAHARPER AND ROW PUBLISHERS THEN JB LIPPINCOTT COMPANY-. 2002;27(9):949-53. 9. Epstein NE, Hollingsworth R, Nardi D, Singer J. Can airway complications following multilevel anterior cervical surgery be avoided? Journal of Neurosurgery: Spine. 2001;94(2):185-8.
10. Emery SE, Smith M, Bohlman H. Upper-airway obstruction after multilevel cervical corpectomy for myelopathy. J Bone Joint Surg Am.

1991;73(4):544-51.

11. Hofstetter CP, Kesavabhotla K, Boockvar JA.

Zero-profile anchored spacer reduces rate of dysphagia compared with $\mathrm{ACDF}$ with anterior plating. Clinical Spine Surgery. 2015;28(5):E284-E90.

12. Son DK, Son DW, Kim HS, Sung SK, Lee SW, Song GS. Comparative study of clinical and radiological outcomes of a zero-profile device concerning reduced postoperative Dysphagia after single level anterior cervical discectomy and fusion. Journal of Korean Neurosurgical Society. 2014;56(2):103-7.

13. Lee S-H, Kim K-T, Suk K-S, Park K-J, Oh K-I. Effect of retropharyngeal steroid on prevertebral soft tissue swelling following anterior cervical discectomy and fusion: a prospective, randomized study. Spine. 2011;36(26):2286-92.

14. Association AS-LH. National Outcomes Measurements System (NOMS): Adult SpeechLanguage Pathology Training Manual. American Speech-Language Hearing Association, Rockville (Maryland). 1998.

15. Anastasi A. Psychological testing. 1968.

16. Parrott A. Performance tests in human psychopharmacology (2): content validity, criterion validity, and face validity. Human Psychopharmacology: Clinical and Experimental. 1991;6(2):91-8.

17. Sclafani J, Raiszadeh K, Raiszadeh R, Kim P, Doerr T, Siddiqi F, et al. Validation and analysis of a multi-site MIS Prospective Registry through subanalysis of an MIS TLIF Subgroup. International journal of spine surgery. 2014;8(1):4-.

18. Ware JE, Kosinski M, Dewey JE, Gandek B. SF-36 health survey: manual and interpretation guide: Quality Metric Inc.; 2000.

19. Wessa P. Cronbach alpha (v1. 0.1) in Free Statistics Software (v1. 1.23-r6). Office for Research Development and Education [online].

https://www.wessa.net/rwasp_cronbach.wasp. 2011. 20. Kepler CK, Rihn JA, Bennett JD, Anderson DG, Vaccaro AR, Albert TJ, et al. Dysphagia and soft-tissue swelling after anterior cervical surgery: a radiographic analysis. The Spine Journal.

2012;12(8):639-44.

21. Rueger RG. Benign disease of the thyroid gland 
and vocal cord paralysis. The Laryngoscope. 1974;84(6):897-907.

22. HONG KH, KIM YK. Phonatory characteristics of patients undergoing thyroidectomy without laryngeal nerve injury. Otolaryngology-Head and Neck Surgery. 1997;117(4):399-404.

23. Njoku Jr I, Alimi M, Leng LZ, Shin BJ, James AR, Bhangoo $S$, et al. Anterior cervical discectomy and fusion with a zero-profile integrated plate and spacer device: a clinical and radiological study: clinical article. Journal of Neurosurgery: Spine.

2014;21(4):529-37.

24. Scholz M, Reyes PM, Schleicher P, Sawa AG, Baek S, Kandziora F, et al. A new stand-alone cervical anterior interbody fusion device: biomechanical comparison with established anterior cervical fixation devices. Spine. 2009;34(2):156-60.

25. Lee MJ, Bazaz R, Furey CG, Yoo J. Influence of anterior cervical plate design on dysphagia: a 2-year prospective longitudinal follow-up study. Journal of spinal disorders \& techniques. 2005;18(5):406-9.

26. Moerman MB. Cricopharyngeal Botox injection: indications and technique. Current opinion in otolaryngology \& head and neck surgery. 2006;14(6):431-6.

27. Pitman M, Weissbrod P. Endoscopic CO2 laser cricopharyngeal myotomy. The Laryngoscope. 2009;119(1):45-53.

28. Chang CY, Payyapilli RJ, Scher RL. Endoscopic staple diverticulostomy for Zenker's diverticulum: review of literature and experience in 159 consecutive cases. The Laryngoscope. 2003;113(6):957-65. 29. Brady S, Donzelli J. The modified barium swallow and the functional endoscopic evaluation of swallowing. Otolaryngologic Clinics of North America. 2013;46(6):1009-22.

30. Rao N, Brady S, Chaudhuri G, Donzelli J, Wesling M. Gold-standard? Analysis of the videofluoroscopic and fiberoptic endoscopic swallow examinations. J Applied Res. 2003;3(1):1-8.

31. Schatz K, Langmore SE, Olson N. Endoscopic and videofluoroscopic evaluations of swallowing and aspiration. Annals of Otology, Rhinology \& Laryngology. 1991;100(8):678-81.

\section{Disclosures \& COI}

The authors report no relevant disclosures.

\section{Corresponding Author}

Dr. Joseph Sclafani, Spine Institute of San Diego, Minimally Invasive Spine Center of Excellence, San Diego, CA.

Published 5 December 2017.

This manuscript is generously published free of charge by ISASS, the International Society for the Advancement of Spine Surgery. Copyright @ 2017 ISASS. To see more or order reprints or permissions, see http://ijssurgery.com. 